\title{
Controversies on Rituximab Therapy in Sjögren Syndrome-Associated Lymphoproliferation
}

\author{
Luca Quartuccio, ${ }^{1}$ Martina Fabris, ${ }^{1}$ Sara Salvin, ${ }^{1}$ Marta Maset, ${ }^{1}$ \\ Ginevra De Marchi, ${ }^{2}$ and Salvatore De Vita ${ }^{1}$ \\ ${ }^{1}$ Rheumatology Clinic, DPMSC, Azienda Ospedaliero Universitaria “S. Maria della Misericordia”, \\ University of Udine, 33100 Udine, Italy \\ ${ }^{2}$ U.O.C. di Medicina, Presidio Ospedaliero di San Daniele del Friuli, San Daniele del Friuli, 33038 Udine, Italy
}

Correspondence should be addressed to Salvatore De Vita, devita.salvatore@aoud.sanita.fvg.it

Received 28 February 2009; Accepted 15 December 2009

Recommended by Debashish Danda

Sjögren's syndrome (SS) is a systemic autoimmune disease characterized by chronic inflammation of salivary and lachrymal glands, and frequently accompanied by systemic symptoms. A subgroup of SS patients develops malignant B cell non-Hodgkin's lymphoma (NHL), usually of the mucosa-associated lymphoid tissue (MALT) type and very often located in the major salivary glands. Currently, there is a lack of evidence-based intervention therapy which may influence SS-related chronic inflammation and lymphoproliferation. B cells are involved in the pathogenesis of SS, and B cell downregulation may lead to a decrease of disease activity. Rituximab (RTX), a chimeric monoclonal antibody targeting the CD20 antigen on the B cell surface, has been successfully investigated in other autoimmune diseases, such as rheumatoid arthritis, systemic lupus erythematosus, ANCAassociated vasculitis, and mixed cryoglobulinemic syndrome. Preliminary experiences of RTX therapy in SS patients with or without a lymphoproliferative disorder suggest that SS patients with more residual exocrine gland function might better benefit from RTX. Efficacy of RTX in SS-associated B-cell lymphoma, mainly in low-grade salivary gland lymphomas, remains an open issue.

Copyright ( 92009 Luca Quartuccio et al. This is an open access article distributed under the Creative Commons Attribution License, which permits unrestricted use, distribution, and reproduction in any medium, provided the original work is properly cited.

\section{Introduction}

Sjögren's syndrome (SS) is a systemic autoimmune disease characterized by chronic inflammation of salivary and lachrymal glands, frequently accompanied by systemic symptoms [1]. The presence of various autoantibodies such as the rheumatoid factor (RF) and anti-SSA/SSB antibodies, as well as hypergammaglobulinemia, reflects $B$ cell hyperactivity [1]. SS has the strongest link with non-Hodgkin's lymphoma (NHL) compared with other autoimmune diseases, and similar to mixed cryoglobulinemic syndrome, which may be associated with SS [2-4]. About five percent of patients with SS develop a malignant B cell NHL, usually of the mucosa-associated lymphoid tissue (MALT) type and frequently located in the parotid glands $[1,5]$. Currently, there is a lack of evidence-based intervention therapy which may influence SS-related chronic inflamma- tion and lymphoproliferation. In particular, the optimal treatment for NHL complicating SS is not clearly defined. The majority of SS patients with indolent NHL may require only surveillance and no therapy; however, a subgroup of SS patients may suffer from aggressive lymphomas, that is, de novo diffuse large cell B-cell lymphomas, or indolent or lowgrade lymphomas progressed into aggressive lymphomas [2]. Although SS has been regarded as T-cell-mediated disease, B cells comprise in general up to $20 \%$ of the mononuclear cells in the salivary glands $[1,6]$. B-cell activating factor (BAFF) promotes B-cell survival and differentiation, and SS patients frequently have elevated serum levels of BAFF [7]. BAFF overproduction in mouse models results in several autoimmune phenomena, resembling SS and lupus features, as well as in B-cell hyperplasia and lymphoma development $[8,9]$. Thus, B cells are involved in the pathogenesis of SS, and $\mathrm{B}$ cell downregulation may be a target of treatment. 
Rituximab (RTX), a chimeric monoclonal antibody direct against the CD20 molecule expressed on the surface of mature B cells, is then a putative therapy for both sicca syndrome and SS-related B-cell lymphoproliferation [10]. Patients with more residual exocrine gland function, for example, those with SS of shorter duration, might better benefit from systemic therapy, as well as SS patients with the cryoglobulinemic syndrome, as reported in recent studies $[11,12]$. However, in earliest experience reported between the years 2000 and 2002 by our group, RTX efficacy on nonmalignant lymphoproliferation in SS was inconstant, and a scarce effect on sicca symptoms was observed [13]. Then, a careful use of RTX in selected cases seemed more rationale, in the lack of additional clear-cut evidence of some benefits. By contrast, RTX monotherapy or RTX combined with cytotoxic agents in chemotherapeutic regimens may have a stronger rationale in SS patients with CD20-positive B-cell NHL $[3,11,14-22]$.

\section{Pathologic and Molecular Background, and Involvement of BAFF}

Low-grade marginal zone MALT-type lymphoma, usually involving the parotid glands, is an important complication of primary SS [1, 2, 23-25]. A 250-fold increase in risk of parotid gland NHL and a dramatic 1000 -fold increase in risk of parotid gland MALT lymphoma were recently observed [2]. However, a positive associations between SS and other subtypes, most notably diffuse large B-cell lymphoma and nodal lymphomas, was reported [2]. Parotid lymphoma may evolve from parotid lymphoepithelial sialadenitis (LESA), which may in turn present with different pathologic and molecular patterns of B cell proliferation, that is, fully benign or with lymphoproliferative lesion by histopathology; and poly-, oligo-, or monoclonal-fluctuating, -persistent or -disseminated by molecular studies [23]. A notable histological feature in SS is LESA characterized by a lymphoid population surrounding and infiltrating salivary ducts, with disorganization and proliferation of the ductal epithelial cells (lymphoepithelial lesions) [26]. These lesions first appear as small clusters and later enlarge to organize lymphoid folliclelike structures with germinal centers. The phenotype of the immunocompetent cells present in lymphoepithelial lesions, mainly composed of primed CD4+ T lymphocytes, suggests functional structures in which activated B cells produce autoantibodies [27-29]. Therefore, LESA is a condition in which MALT is found in the salivary glands, a site not normally containing lymphoid tissue. The MALT acquired due to the autoimmune process may represent the substrate from which the B cell lymphoma develops in SS $[1,23,30]$.

The characterization of the earlier events of lymphoproliferation in SS is still ill-defined. Because a monoclonal expansion does not necessarily constitute a malignant lymphoma, monoclonal B cell populations in early LESA represent nonmalignant expansions rather than an early NHL, at least in most cases [23]. The presence of the same $\mathrm{B}$-cell clone in metachronous biopsies of the same affected tissue from the same patient indicates a higher risk of NHL evolution, while different clones in metachronous biopsies are consistent with a nonmalignant B-cell expansion [23, 31]. Thus, the different types of $B$ cell clonal expansion (oligoclonal or monoclonal, smaller or larger, fluctuating or established, localized or disseminated) in SS salivary MALT imply a different risk of lymphoma progression in our experience. Since the transition of LESA into a malignant lymphoma is generally considered to represent a multistep process, molecular studies of clonal B-cell expansion appear of value to better define the risk of lymphoma evolution in SS [23]. It has been speculated that lymphoproliferation is driven by antigenic stimulation, and that during the course of the disease additional oncogenic events occur, such as constitutive activation of signaling pathways after chromosomal translocations or inactivation of tumor suppressor genes.

Cytokine and chemokine microenvironments in target tissues may play a role in the lymphoproliferation in the course of SS. Recently, Barone et al. demonstrated the association between lymphoid chemokines CXCL13 and CCL21 and areas of reactive lymphoid proliferation in the salivary glands with LESA, while CXCL12 was observed predominantly in infiltrated ducts and malignant B cells, suggesting that in salivary gland MALT lymphoma, the lymphoid chemokines CXCL13 and CCL21 are directly implicated in the organization of ectopic lymphoid germinal centers, whereas CXCL12 is associated with the infiltrated epithelium and malignant $\mathrm{B}$ cell component and is possibly involved in the regulation of malignant $\mathrm{B}$ cell survival [32]. The differential expressions of CXCL13, CCL21, and CXCL12 within SS salivary glands with LESA and MALTLymphoma regulate diverse functional microenvironments of lymphoid organization, respectively orchestrating the reactive lymphoid areas that favor the perpetuation of the autoreactive response and the malignant areas where expansion and proliferation of the B cell clones take place [32].

Overproduction of BAFF, implicated in the maturation and survival of B lymphocytes, may play a role in the mechanism of salvage of autoreactive B cell (e.g., RF-positive $\mathrm{B}$-cells) and in the B-cell hyperplasia, as demonstrated in mouse models. Mice carrying a transgene for BAFF become highly susceptible to the autoimmunity-lymphoproliferation complex development $[8,9]$. Analysis of BAFF plasma levels in SS has shown that BAFF is higher in patients than in controls and strongly correlates with the titer of autoantibodies such as RF and anti-Ro/SSA [7]. A strong expression of BAFF was also detected in infiltrating lymphocytes, in ductal and acinar epithelial cells in target tissue biopsies from SS patients [20,33-35]. The prolonged survival of autoreactive $\mathrm{B}$ cells may promote production of autoantibodies or the later development of NHL in SS patients. Finally, $\mathrm{TNF}^{-/-}$ BAFF transgenic mice also showed a high incidence of B cell lymphomas [36].

RTX exposure increases BAFF overproduction [12, 20]. Recently, we described in detail one of reported SS cases with lymphoma undergoing RTX therapy [20]. In such a case, BAFF overproduction after RTX administration was decreased, but not halted by high-dose steroids (prednisone $1 \mathrm{mg} / \mathrm{kg} / \mathrm{day}$ for one month). However, BAFF 
overproduction reappeared at even higher levels after steroid dose reduction. Pre- and post-RTX parotid gland biopsies demonstrated the persistence of BAFF and BAFF-receptor overexpression at the histopathologic and molecular level [20]. Lymphoma in this patient did not respond to RTX therapy, and BAFF was considered as a key resistance factor [20].

In a second case of SS with parotid LESA, who developed rheumatoid arthritis after interferon-alpha therapy for SS, RTX therapy was administered at time of relapse of polysynovitis in a long-term period of follow-up (107 months), with 4 complete cycles of RTX and 6 subsequent single doses of RTX every 6-12 months. Repeated parotid biopsy after 4 full RTX cycles given in 3,5 years revealed a reduction in the parotid lymphoid infiltrate and recovery of acinar and lobular structures at histopathologic level. However, PAN$\mathrm{B}$ and PAN-T antibody stains disclosed a very large amount of $\mathrm{B}$ and $\mathrm{T}$ cell infiltrates, similar to baseline analysis. Thus, prolonged RTX therapy, that is, at least 4 full cycles, may not affect parotid lymphoproliferation in SS. Pers et al. [37] demonstrated that baseline serum levels of BAFF correlated inversely with the duration of B cell depletion after RTX in SS. B cells were absent in salivary glands analysed 12 months after RTX therapy in sequential lip biopsies, but they were again detected 24 months after RTX. Memory and transitional type 1 (T1) B cells were the first repopulating B cells. Recovery of salivary gland B cells occurred with four B cell subsets: plasmablasts, T1 B cells, mature Bm2 cells, and memory B cells. Increased numbers of Bm2 cells and decreased memory $B$ cells reappeared with time. B cell repopulation in SS glands may be modulated by BAFF and, notably, is followed by reconstitution of the preexisting abnormalities [37].

By integrating the clinical and molecular results herein presented, the concept that BAFF plays a crucial role in Bcell proliferation in the course of SS, at least in a subset of patients, is reinforced, and BAFF tissue overexpression may therefore represent a mechanism of RTX resistance in B-cell lymphoproliferation associated with SS.

\section{Data from Case Reports and from Open-Label Trials}

Since 2002 up to the time of searching (February 2009), 26 patients with SS and lymphoma treated with RTX have been reported in 11 PubMed indexed articles by combining the key words "Sjögren's syndrome", "rituximab", and "lymphoma" [3, 11, 14-22]. Sixteen (17/26) were in Ann Arbor Stage I-II, while the remaining were in stage III (1/26) or IV (8/26). Thirteen (14/26) were salivary gland MALTtype lymphomas, mainly parotid gland MALT-type lymphomas (11/26). In 10/26 patients, RTX was administered in combination with other cytotoxic agents (with cyclophosphamide/doxorubicin/vincristine/prednisone (CHOP) regimen in 9 patients, with cyclophosphamide/vincristine/ prednisone (CVP) regimen in 1), while in the remaining 16 cases RTX was used in monotherapy (9/26), or with methylprednisolone pulses, low to medium doses of steroids, antimalarials, methotrexate, azathioprine (5/26), or after local radiotherapy $(1 / 26)$. Globally, response rate to RTX (alone or added to chemotherapy) in SS-related B-cell NHL was $20 / 26(77 \%)$.

However, while all the ten patients treated with combined therapy with RTX plus cytotoxic agents in chemotherapeutic regimens had a good outcome, response was observed in $10 / 16(62,5 \%)$ of the 16 cases treated with RTX without cytotoxic therapy. Of the 10 NHLs responding to RTX without chemotherapy, 8 were in I-II Ann Arbor stage (treated with RTX monotherapy) and two were in IV Ann Arbor stage (one also treated with local radiotherapy). Six out of the 10 NHLs responding to RTX without chemotherapy had salivary MALT-type lymphomas, and the other 4 disclosed nonsalivary MALT-type lymphomas. Interestingly, all the nonresponding lymphomas (6/6) involved the salivary glands (Table 1). Thus, salivary gland NHLs, if compared to MALT NHLs involving other organs, seemed more resistant to RTX therapy in the lack of concomitant chemotherapy.

Finally, a higher incidence of human antichimeric antibodies (HACA) and serum sickness reaction was reported after RTX in SS., if compared to other autoimmune diseases $[12,19]$.

\section{Personal Experience}

Early data on SS patients treated with RTX were presented by our Group in 2002 [13], showing a lack of effect of RTX on nonmalignant parotid monoclonal B-cell lymphoproliferation in LESA. Unexpectedly, lung NHL in one of these two cases showed persistent regression after RTX [12]. At present, we have treated 6 SS patients with RTX in the attempt to improve SS-related manifestations. Indications for RTX were the following: B-cell NHL in 4 patients and nonmalignant parotid lymphoproliferation in 2 patients (LESA; one of them also with cryoglobulinemic syndrome). Other clinical manifestations are described in Table 2, including rheumatoid arthritis in one patient with parotid LESA [38]. RTX was administered at the standard haematological doses, that is, $375 \mathrm{mg} / \mathrm{m}^{2}$ weekly for 4 weeks. One patient underwent two subsequent full cycles of RTX, and another patient underwent 4 full cycles and then 6 single $(600 \mathrm{mg})$ RTX infusions at the time of rheumatoid arthritis relapse. Sicca syndrome responded much better in the patient's perspective than in clinical objective evaluation, with about half of the patients reporting an improvement in oral and ocular dryness, while objective tests (i.e., Schirmer test and unstimulated sialometry) remained unchanged or worsened in all the patients. However, constitutional symptoms such as fatigue, low-grade fever, arthralgias, and myalgias, improved in all patients. Parotid swelling decreased or disappeared in 5/6 patients. Cutaneous vasculitis responded in $2 / 3$ patients; sensory peripheral neuropathy improved in $2 / 3$ patients; polysynovitis improved in 3/4 patients. Cryoglobulins and the RF (when present) decreased but did not become negative at month +6 , and anti-SSA/SSB autoantibodies remained positive in all the 6 cases. Lymphoma histotypes 
TABLE 1: Patients with SS and lymphoma treated with rituximab.

\begin{tabular}{|c|c|c|c|c|c|}
\hline Author, years & N. of pts & $\begin{array}{l}\text { Type of lymphoma/bone marrow } \\
\text { involvement }\end{array}$ & $\begin{array}{l}\text { Ann Arbor } \\
\text { Stage }\end{array}$ & $\begin{array}{l}\text { Response } \\
\text { on } \\
\text { lymphoma }\end{array}$ & $\begin{array}{l}\text { Other concomitant } \\
\text { treatments for lymphoma }\end{array}$ \\
\hline Shih, 2002 & 1 & Parotid gland MALT-type/no & IE & Yes & No \\
\hline Somer, 2003 & 1 & Parotid gland MALT-type/no & IE & Yes & No \\
\hline \multirow{4}{*}{ Voulgarelis, 2004* } & \multirow{4}{*}{4} & (1) Salivary gland MALT-type/yes* & IV & Yes & (1) $\mathrm{CHOP}$ \\
\hline & & (2) Nodal marginal zone/no* & IIE & Yes & (2) $\mathrm{CHOP}$ \\
\hline & & (3) Pulmonary MALT-type/yes* & IV & Yes & (3) $\mathrm{CHOP}$ \\
\hline & & (4) Salivary gland MALT-type/yes* & IV & Yes & (4) $\mathrm{CHOP}$ \\
\hline Harner, 2004 & 1 & $\begin{array}{l}\text { Nodal marginal zone/Pulmonary } \\
\text { MALT-type/no }\end{array}$ & IIE & Yes & No \\
\hline \multirow{2}{*}{ Ramos-Casals, 2004} & \multirow{2}{*}{2} & (1) Ovarian MALT-type/yes & IV & Yes & (1) $\mathrm{CHOP}$ \\
\hline & & (2) Ocular MALT-type/yes & IV & Yes & (2) Local radiotherapy \\
\hline Pijpe, 2005 & 1 & Parotid gland MALT-type/no & IE & Yes & No \\
\hline \multirow{2}{*}{ Gottenberg, 2005 } & \multirow{2}{*}{2} & (1) Digestive tract MALT-type/no ${ }^{\#}$ & IE & Yes & (1) MP $500 \mathrm{mg} \times 4$, HQ \\
\hline & & (2) Salivary gland MALT-type/no & IE & No & (2) No \\
\hline \multirow{7}{*}{ Pijpe, 2005} & \multirow{7}{*}{7} & (1) Parotid gland MALT-type/no & IE & No & (1) No \\
\hline & & (2) Parotid gland MALT-type/no & IE & No & (2) PDN 15 mg/day \\
\hline & & (3) Parotid gland MALT-type/no & IE & Yes & (3) No \\
\hline & & (4) Parotid gland MALT-type/no & IE & Yes & (4) No \\
\hline & & (5) Parotid gland MALT-type/no & IE & No & (5) PDN 7.5 mg/day, MTX \\
\hline & & (6) Parotid gland MALT-type/no & IE & Yes & (6) PDN 5 mg/day, AZA \\
\hline & & (7) Parotid gland MALT-type/no & IE & No & $(7)$ No \\
\hline \multirow{6}{*}{ Voulgarelis, 2006* } & \multirow{6}{*}{6} & (1) Nodal marginal zone/no & II & Yes & (1) $\mathrm{CHOP}$ \\
\hline & & (2) DLBCL/no & II & Yes & (2) $\mathrm{CHOP}$ \\
\hline & & (3) Salivary gland MALT-type/yes* & IV & Yes & (3) $\mathrm{CHOP}$ \\
\hline & & (4) Nodal marginal zone/no* & IIE & Yes & (4) $\mathrm{CHOP}$ \\
\hline & & (5) Pulmonary MALT-type/yes* & IV & Yes & (5) $\mathrm{CHOP}$ \\
\hline & & (6) Salivary gland MALT-type/yes* & IV & Yes & (6) $\mathrm{CHOP}$ \\
\hline \multirow{5}{*}{ Seror, $2007^{\#}$} & \multirow{5}{*}{5} & (1) Salivary gland MALT-type/no ${ }^{\#}$ & IE & No & (1) No \\
\hline & & (2) Nodal marginal zone/yes & IV & Yes & (2) No \\
\hline & & (3) Gastric/pulmonary MALT-type/no & IV & Yes & (3) Mini-CHOP \\
\hline & & (4) Gastric MALT-type/no ${ }^{\#}$ & IE & Yes & (4) HQ \\
\hline & & (5) $\mathrm{DLBCL} /$ no & III & Yes & (5) $\mathrm{CHOP}$ \\
\hline Quartuccio, $2008^{\circ}$ & 1 & Parotid gland MALT-type $/$ no $^{\circ}$ & IE & No & High-dose steroids \\
\hline Carbone J, 2008 & 1 & Low-grade marginal zone/yes & IV & Yes & CVP \\
\hline \multirow{4}{*}{ Present report $^{\circ}$} & \multirow{4}{*}{4} & Parotid gland MALT-type $/$ no $^{\circ}$ & IE & No & High-dose steroids \\
\hline & & Lung MALT-type /no & IE & Yes & No \\
\hline & & DLBCL + salivary MALT-type/no & IV & Yes & CNOP \\
\hline & & Parotid gland MALT-type/yes & IV & Yes & Parotidectomy \\
\hline
\end{tabular}

Legend: pts, patients; MALT, mucosa-associated lymphoid tissue; CHOP, cyclophosphamide, doxorubicin, vincristine, prednisone; AZA, azathioprine; PDN, prednisone; MTX, methotrexate; MP, methylprednisolone; DLBCL, diffuse large B-cell lymphoma; HQ, hydroxychloroquine.

* There is some patients' overlapping between the cases reported in Voulgarelis, 2004 and Voulgarelis, 2006.

\#There is some patients' overlapping between the cases reported in Gottenberg, 2005 and Seror, 2007.

${ }^{\circ}$ There is some patients' overlapping between the cases reported in Quartuccio, 2008 and present report.

and staging were one parotid MALT-type low-grade B-cell NHL (stage IE) [20], one lung MALT-type low-grade Bcell NHL associated with parotid LESA (stage IE) [10, 23], one aggressive diffuse large B-cell NHL associated with salivary MALT-type low-grade B-cell NHL (stage IV), and one parotid gland low-grade MALT-type B-cell NHL with bone marrow NHL infiltration (stage IV). RTX combination therapy with cytotoxic agents was administered in one patient (aggressive diffuse large B-cell lymphoma). One patient underwent monolateral parotidectomy before RTX 


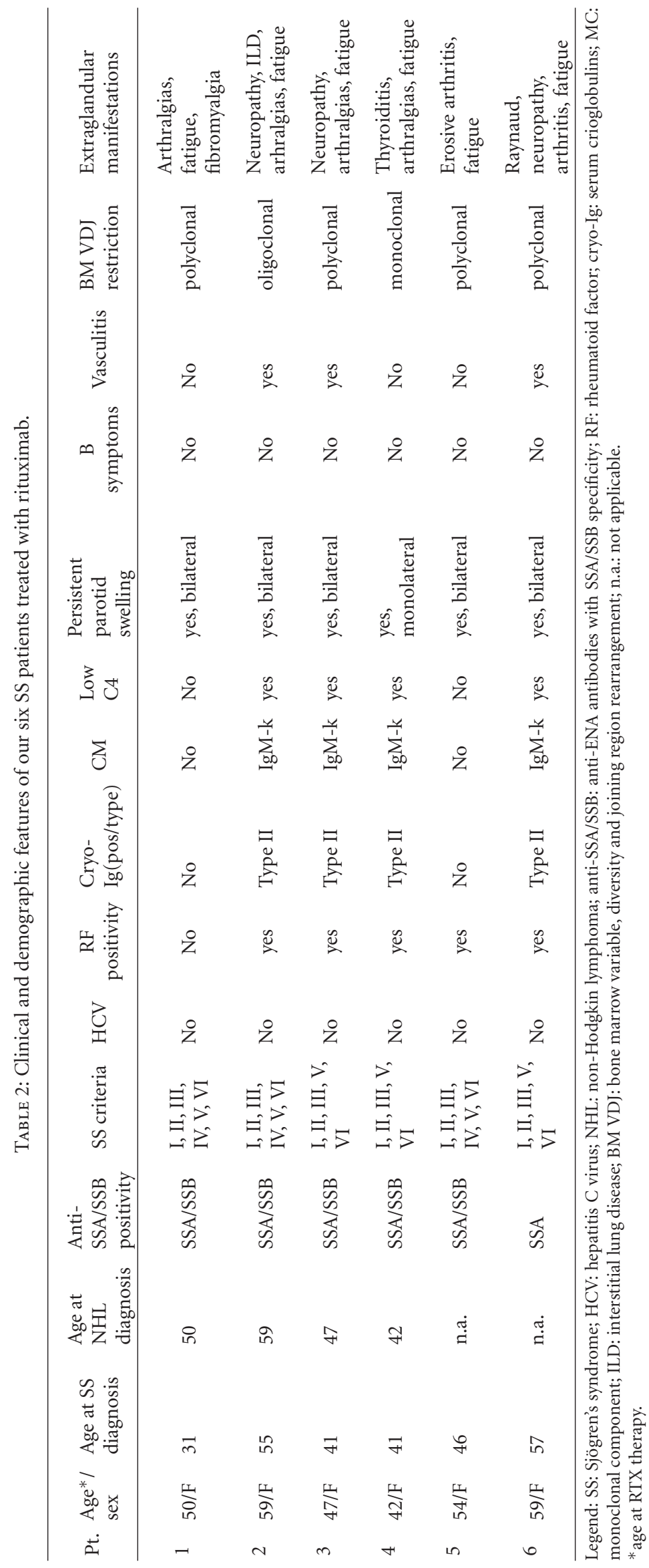


(parotid gland MALT-type monolateral lymphoma with bone marrow infiltration). Complete response was observed in 3/4 NHL patients, with no relapse in the long-term followup (mean survival time 5.5 years). One patient died for right heart failure at month +39 (secondary to severe mitral and tricuspidal valve insufficiency). Of note, in the patient with lung MALT-type low-grade NHL associated with parotid LESA, biopsy-demonstrated [10, 23], a complete response to RTX monotherapy was observed in lung MALT-type lymphoma, while nonmalignant proliferation (LESA) in the parotid glands persisted [10] with parotid swelling still evident at present.

Treatment with RTX was well tolerated. Serum sickness reactions were not recorded.

Overall, RTX proved effective on SS systemic symptoms, ineffective on sicca syndrome, ineffective on LESA (documented by repeated biopsy) [10,23], and of value, alone or added to chemotherapy, in SS-related NHL.

\section{Conclusion}

Despite the efficacy of RTX in constitutional and systemic features associated with B cell expansion in SS (i.e. cryoglobulinemic vasculitis) [12], the usefulness of RTX in Bcell lymphoproliferation in SS is controversial. Aggressive lymphomas require standard chemotherapeutic regimens, which were recently integrated with RTX [15]. However, the majority of SS patients with lymphoma show indolent, nonaggressive lymphomas, mainly salivary (parotid) MALT-type lymphomas in stage I-II, with a performance status 0-1 [39]. An aggressive approach would be more dangerous rather than curative in this subset. Parotid MALTtype NHL associated with SS appears to be to be more resistant to RTX as compared with the other types of lymphoma in SS, and RTX may be as well ineffective in SS-related LESA. RTX may fail to deplete B-cells in the salivary tissue due to key pathogenetic factors in the local microenvironment, as recently well described in a murine model [40]. A still unknown local trigger is also suspected. Local factors such as BAFF and chemokines (CXCL13, CCL21, CXCL12) appear to be implicated, and BAFF inhibition plus anti-CD20 therapy allowed reaching much higher degrees of B-cell depletion in mouse models [40].

Thus, by integrating clinical and molecular data, RTX monotherapy may not represent an ideal treatment for SSassociated lymphoproliferation, and B-cell recovery after RTX, when present, showed the restoration of previous B-cell abnormalities [37]. Combining RTX with cytotoxic agents in aggressive lymphomas, or with the recently available antiBAFF agents in indolent lymphomas and prelimphomatous conditions (e.g., persistent parotid swelling with ongoing monoclonal B-cell expansion, and/or type II mixed cryglobulinemia) could prove more effective, and dedicated studies are needed. Persistence of antigen-driven stimulation of the immune system in the target tissue may finally require an etiologic treatment, as in gastric low grade NHL [41].

\section{References}

[1] F. N. Skopouli, U. Dafni, J. P. A. Ioannidis, and H. M. Moutsopoulos, "Clinical evolution, and morbidity and mortality of primary Sjögren's syndrome," Seminars in Arthritis and Rheumatism, vol. 29, no. 5, pp. 296-304, 2000.

[2] K. E. Smedby, C. M. Vajdic, M. Falster, et al., "Autoimmune disorders and risk of non-Hodgkin lymphoma subtypes: a pooled analysis within the InterLymph Consortium," Blood, vol. 111, no. 8, pp. 4029-4038, 2008.

[3] B. G. Somer, D. E. Tsai, L. Downs, B. Weinstein, and S. J. Schuster, "Improvement in Sjögren's syndrome following therapy with rituximab for marginal zone lymphoma," Arthritis Care and Research, vol. 49, no. 3, pp. 394-398, 2003.

[4] S. De Vita, V. De Re, D. Gasparotto, et al., "Oligoclonal non-neoplastic B cell expansion is the key feature of type II mixed cryoglobulinemia: clinical and molecular findings do not support a bone marrow pathologic diagnosis of indolent B cell lymphoma," Arthritis and Rheumatism, vol. 43, no. 1, pp. 94-102, 2000.

[5] S. De Vita, G. De Marchi, S. Sacco, E. Gremese, M. Fabris, and G. Ferraccioli, "Preliminary classification of nonmalignant B cell proliferation in Sjögren's syndrome: perspectives on pathobiology and treatment based on an integrated clinicopathologic and molecular study approach," Blood Cells, Molecules, and Diseases, vol. 27, no. 4, pp. 757-766, 2001.

[6] M. Voulgarelis and F. N. Skopouli, "Clinical, immunologic, and molecular factors predicting lymphoma development in Sjögren's syndrome patients," Clinical Reviews in Allergy and Immunology, vol. 32, no. 3, pp. 265-274, 2007.

[7] X. Mariette, S. Roux, J. Zhang, et al., "The level of BLyS (BAFF) correlates with the titre of autoantibodies in human Sjögren's syndrome," Annals of the Rheumatic Diseases, vol. 62, no. 2, pp. 168-171, 2003.

[8] F. Mackay, F. Sierro, S. T. Grey, and T. P. Gordon, "The BAFF/APRIL system: an important player in systemic rheumatic diseases," Current Directions in Autoimmunity, vol. 8, pp. 243-265, 2005.

[9] F. Mackay, S. A. Woodcock, P. Lawton, et al., "Mice transgenic for BAFF develop lymphocytic disorders along with autoimmune manifestations," Journal of Experimental Medicine, vol. 190, no. 11, pp. 1697-1710, 1999.

[10] D. Gasparotto, S. De Vita, V. De Re, et al., "Extrasalivary lymphoma development in Sjögren's syndrome: clonal evolution from parotid gland lymphoproliferation and role of local triggering," Arthritis and Rheumatism, vol. 48, no. 11, pp. 3181-3186, 2003.

[11] J. Pijpe, G. W. van Imhoff, A. Vissink, et al., "Changes in salivary gland immunohistology and function after rituximab monotherapy in a patient with Sjögren's syndrome and associated MALT lymphoma," Annals of the Rheumatic Diseases, vol. 64, no. 6, pp. 958-960, 2005.

[12] R. Seror, C. Sordet, L. Guillevin, et al., "Tolerance and efficacy of rituximab and changes in serum B cell biomarkers in patients with systemic complications of primary Sjögren's syndrome," Annals of the Rheumatic Diseases, vol. 66, no. 3, pp. 351-357, 2007.

[13] S. De Vita, G. De Marchi, S. Sacco, F. Zaja, C. A. Scott, and G. Ferraccioli, "Treatment of B-cell disorders of MALT in Sjögren's syndrome with anti-CD20 monoclonal antibody," in Proceedings of the 8th International Symposium on Sjögren's Syndrome, p. 51, Kanazawa, Japan, May 2002, P8-2. 
[14] W.-J. Shih, N. Ghesani, Z. Hongming, A. Alavi, S. Schusper, and D. Mozley, "F-18 FDG positron emission tomography demonstrates resolution of non-Hodgkin's lymphoma of the parotid gland in a patient with Sjögren's syndrome before and after anti-CD20 antibody rituximab therapy," Clinical Nuclear Medicine, vol. 27, no. 2, pp. 142-143, 2002.

[15] M. Voulgarelis, S. Giannouli, D. Anagnostou, and A. G. Tzioufas, "Combined therapy with rituximab plus cyclophosphamide/doxorubicin/vincristine/prednisone (CHOP) for Sjögren's syndrome-associated B-cell aggressive non-Hodgkin's lymphomas," Rheumatology, vol. 43, no. 8, pp. 1050-1053, 2004.

[16] K. C. Harner, L. W. Jackson, and J. J. Drabick, "Normalization of anticardiolipin antibodies following rituximab therapy for marginal zone lymphoma in a patient with Sjögren's syndrome," Rheumatology, vol. 43, no. 10, pp. 1309-1310, 2004.

[17] M. Ramos-Casals, A. López-Guillermo, P. Brito-Zerón, R. Cervera, and J. Font, "Treatment of B-cell lymphoma with rituximab in two patients with Sjögren's syndrome associated with hepatitis C virus infection," Lupus, vol. 13, no. 12, pp. 969-971, 2004.

[18] J.-E. Gottenberg, L. Guillevin, O. Lambotte, et al., "Tolerance and short term efficacy of rituximab in 43 patients with systemic autoimmune diseases," Annals of the Rheumatic Diseases, vol. 64, no. 6, pp. 913-920, 2005.

[19] M. Voulgarelis, S. Giannouli, A. G. Tzioufas, and H. M. Moutsopoulos, “Long term remission of Sjögren's syndrome associated aggressive B cell non-Hodgkin's lymphomas following combined B cell depletion therapy and CHOP (cyclophosphamide, doxorubicin, vincristine, prednisone)," Annals of the Rheumatic Diseases, vol. 65, no. 8, pp. 1033-1037, 2006.

[20] J. Pijpe, G. W. van Imhoff, F. K. L. Spijkervet, et al., "Rituximab treatment in patients with primary Sjögren's syndrome: an open-label phase II study," Arthritis and Rheumatism, vol. 52, no. 9, pp. 2740-2750, 2005.

[21] L. Quartuccio, M. Fabris, M. Moretti, et al., "Resistance to rituximab therapy and local BAFF overexpression in Sjögren's syndrome-related myoepithelial sialadenitis and low-grade parotid B-cell lymphoma," The Open Rheumatology Journal, vol. 2, pp. 38-43, 2008.

[22] J. Carbone, R. Perez-Fernandez, A. Muñoz, P. Sabin, L. Carreño, and E. Fernandez-Cruz, "Combined therapy with rituximab plus cyclophosphamide/vincristine/prednisone for Sjögren's syndrome-associated B-cell non-Hodgkin's lymphoma," Clinical Reviews in Allergy and Immunology, vol. 34, no. 1, pp. 80-84, 2008.

[23] S. De Vita, G. De Marchi, S. Sacco, E. Gremese, M. Fabris, and G. Ferraccioli, "Preliminary classification of nonmalignant B cell proliferation in Sjögren's syndrome: perspectives on pathobiology and treatment based on an integrated clinicopathologic and molecular study approach," Blood Cells, Molecules, and Diseases, vol. 27, no. 4, pp. 757-766, 2001.

[24] N. Talal and J. J. Bunim, "The development of malignant lymphoma in the course of Sjögren's syndrome," The American Journal of Medicine, vol. 36, no. 4, pp. 529-540, 1964.

[25] S. S. Kassan, T. L. Thomas, H. M. Moutsopoulos, et al., "Increased risk of lymphoma in sicca syndrome," Annals of Internal Medicine, vol. 89, no. 6, pp. 888-892, 1978.

[26] J. A. DiGiuseppe, R. L. Corio, and W. H. Westra, "Lymphoid infiltrates of the salivary glands: pathology, biology, and clinical significance," Current Opinion in Oncology, vol. 8, no. 3, pp. 232-237, 1996.
[27] D. I. Stott, F. Hiepe, M. Hummel, G. Steinhauser, and C. Berek, "Antigen-driven clonal proliferation of B cells within the target tissue of an autoimmune disease. The salivary glands of patients with Sjögren's syndrome," Journal of Clinical Investigation, vol. 102, no. 5, pp. 938-946, 1998.

[28] T. C. Adamson III, R. I. Fox, D. M. Frisman, and F. V. Howell, "Immunohistologic analysis of lymphoid infiltrates in primary Sjögren's syndrome using monoclonal antibodies," Journal of Immunology, vol. 130, no. 1, pp. 203-208, 1983.

[29] D. Boumba, F. N. Skopouli, and H. M. Moutsopoulos, "Cytokine mRNA expression in the labial salivary gland tissues from patients with primary Sjögren's syndrome," British Journal of Rheumatology, vol. 34, no. 4, pp. 326-333, 1995.

[30] S. De Vita, M. Boiocchi, D. Sorrentino, et al., "Characterization of prelymphomatous stages of B cell lymphoproliferation in Sjögren's syndrome," Arthritis and Rheumatism, vol. 40, no. 2, pp. 318-331, 1997.

[31] S. De Vita, V. De Re, D. Gasparotto, et al., "Oligoclonal non-neoplastic B cell expansion is the key feature of type II mixed cryoglobulinemia: clinical and molecular findings do not support a bone marrow pathologic diagnosis of indolent B cell lymphoma," Arthritis and Rheumatism, vol. 43, no. 1, pp. 94-102, 2000.

[32] F. Barone, M. Bombardieri, M. M. Rosado, et al., "CXCL13, CCL21, and CXCL12 expression in salivary glands of patients with Sjögren's syndrome and MALT lymphoma: association with reactive and malignant areas of lymphoid organization," Journal of Immunology, vol. 180, no. 7, pp. 5130-5140, 2008.

[33] F. Lavie, C. Miceli-Richard, J. Quillard, S. Roux, P. Leclerc, and X. Mariette, "Expression of BAFF (BLyS) in T cells infiltrating labial salivary glands from patients with Sjögren's syndrome," Journal of Pathology, vol. 202, no. 4, pp. 496-502, 2004.

[34] P. Szodoray, S. Jellestad, M. O. Teague, and R. Jonsson, "Attenuated apoptosis of B cell activating factor-expressing cells in primary Sjögren's syndrome," Laboratory Investigation, vol. 83, no. 3, pp. 357-365, 2003.

[35] M. Ittah, C. Miceli-Richard, J.-E. Gottenberg, et al., "B cellactivating factor of the tumor necrosis factor family (BAFF) is expressed under stimulation by interferon in salivary gland epithelial cells in primary Sjögren's syndrome," Arthritis Research and Therapy, vol. 8, no. 2, article R51, 2006.

[36] M. Batten, C. Fletcher, L. G. Ng, et al., "TNF deficiency fails to protect BAFF transgenic mice against autoimmunity and reveals a predisposition to B cell lymphoma," Journal of Immunology, vol. 172, no. 2, pp. 812-822, 2004.

[37] J.-O. Pers, V. Devauchelle, C. Daridon, et al., "BAFFmodulated repopulation of $\mathrm{B}$ lymphocytes in the blood and salivary glands of rituximab-treated patients with Sjören's syndrome," Arthritis and Rheumatism, vol. 56, no. 5, pp. 14641477, 2007.

[38] S. De Vita, F. Zaja, S. Sacco, A. De Candia, R. Fanin, and G. Ferraccioli, "Efficacy of selective B cell blockade in the treatment of rheumatoid arthritis: evidence for a pathogenetic role of B cells," Arthritis and Rheumatism, vol. 46, no. 8, pp. 2029-2033, 2002.

[39] M. Voulgarelis, U. G. Dafni, D. A. Isenberg, and H. M. Moutsopoulos, "Malignant lymphoma in primary Sjögren's syndrome: a multicenter, retrospective, clinical study by the European concerted action on Sjögren's syndrome," Arthritis and Rheumatism, vol. 42, no. 8, pp. 1765-1772, 1999.

[40] Q. Gong, Q. Ou, S. Ye, et al., "Importance of cellular microenvironment and circulatory dynamics in B cell immunotherapy," Journal of Immunology, vol. 174, no. 2, pp. 817-826, 2005. 
[41] A. C. Wotherspoon, C. Doglioni, T. C. Diss, et al., "Regression of primary low-grade-B-cell gastric lymphoma of mucosaassociated lymphoid tissue type after eradication of Helicobacter pylori," The Lancet, vol. 342, no. 8871, pp. 575-577, 1993. 


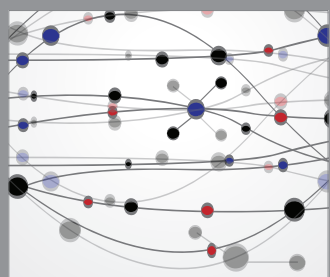

The Scientific World Journal
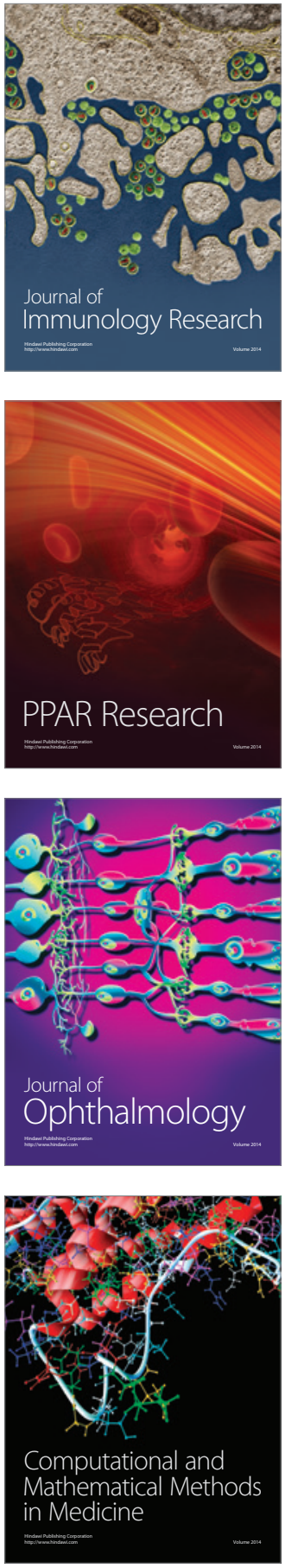

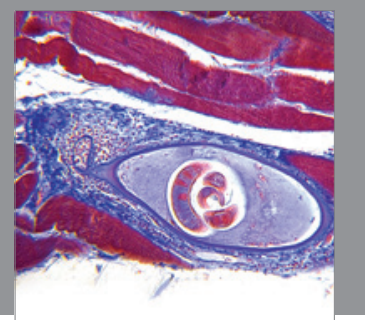

Gastroenterology

Research and Practice
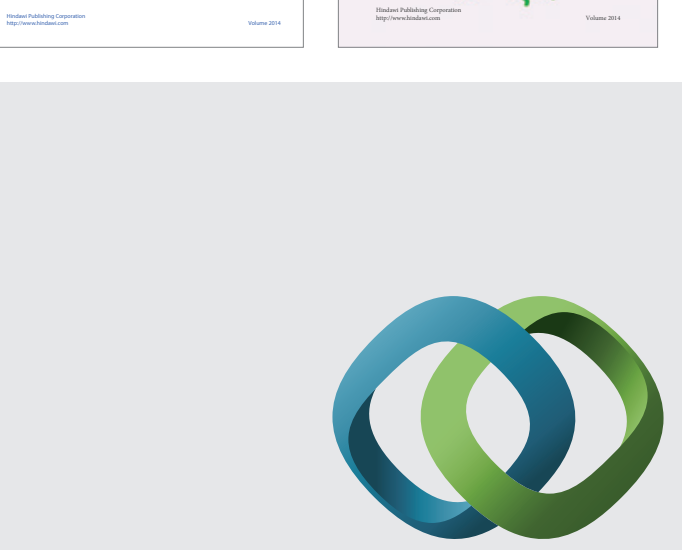

\section{Hindawi}

Submit your manuscripts at

http://www.hindawi.com
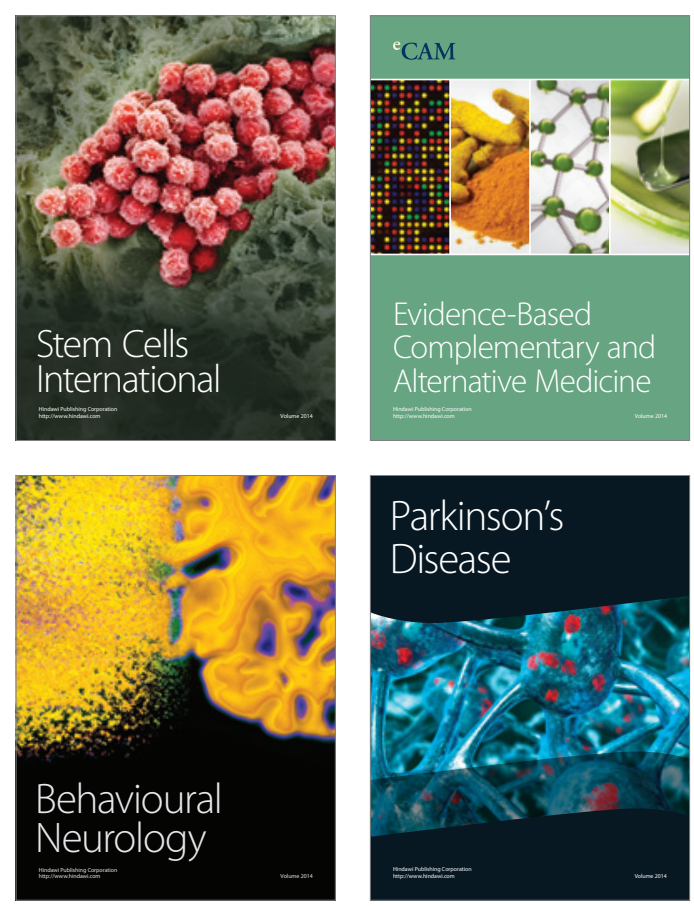

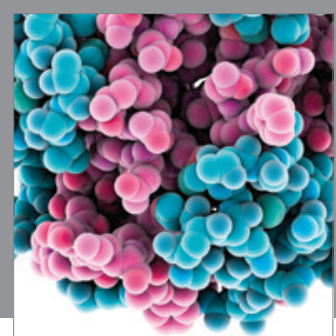

Journal of
Diabetes Research

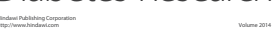

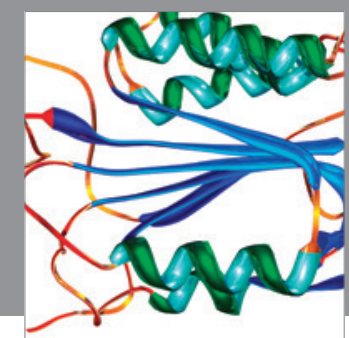

Disease Markers
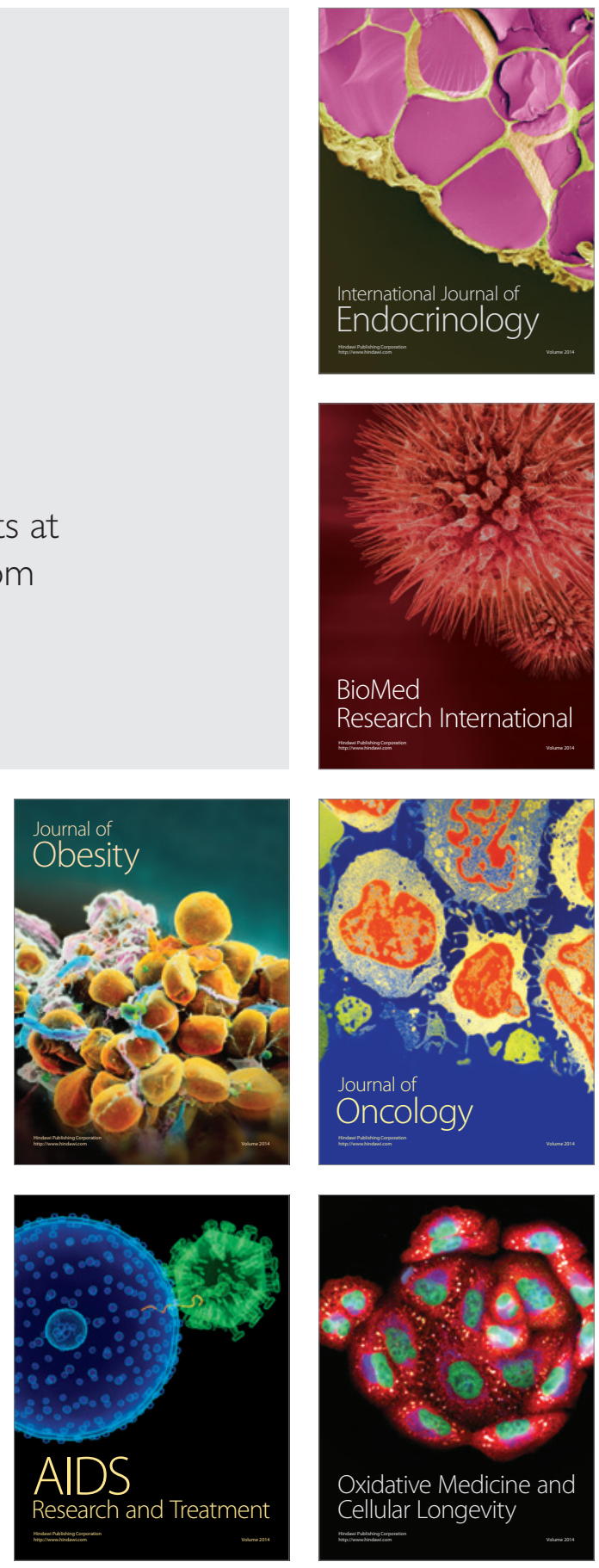